\title{
The implications of landscape visual impact on future highly renewable power systems: a case study for Great Britain
}

\author{
James Price, Kai Mainzer, Stefan Petrović, Marianne Zeyringer, Russell McKenna
}

\begin{abstract}
Recent long term planning studies have demonstrated the important role of variable renewables (VRE) in decarbonising our energy system. However, cost-optimising models do not capture the visual impact of VREs on the landscape which can act to undermine their public acceptability. Here, we use crowd-sourced scenicness data to derive spatially explicit wind energy capacity potentials for three scenarios of public sensitivity to this visual impact. We then use these scenarios in a cost-optimising model of Great Britain's power system to assess their impact on the cost and design of the electricity system in $\mathbf{2 0 5 0}$. Our results show that total system costs can increase by up to $14.2 \%$ when public sensitivity to visual impact is high compared to low. It is thus essential for policy makers to consider these cost implications and to find mechanisms to ameliorate the visual impact of onshore wind in local communities.
\end{abstract}

Index Terms - Power system planning, variable renewable integration, geographic information systems

\section{NOMENCLATURE.}

Sets: $g$

$S$

Z

$\mathrm{t}$

Variables:

$U$

$N$

$U P$

DOWN

$P$

$O R$

$F R$

OR quick $^{\text {in }}$

SCAP

SLEVEL
$F R^{\text {req }}$
OR

Para
af
$p^{\text {max }}$
$p^{\text {min }}$
or
$f r^{\text {max }}$
$s_{-}$or
$s_{-} r^{\text {max }}$
$D E M_{t}$
$D E M^{\text {uncert }}$
VRE
mincert $^{\text {up/down }}$

Energy level of storage (GWh)

Frequency response required $(\mathrm{GW})$

Operating reserve required $(\mathrm{GW})$

\section{INTRODUCTION}

THE decarbonisation of the power sector is key to achieving the headline goal of the Paris Agreement to limit the global mean surface temperature rise to well below $2^{\circ} \mathrm{C}$. Indeed, this sector's importance is only set to grow with the drive to electrify more of the energy system, especially transport and heat. Future very low or net-zero emission power systems must also continue to be equitable and secure. Taken together, these three challenges of energy sustainability, affordability/accessibility and security form the so-called energy trilemma faced by decision makers going forward. In this conceptual model prioritising one of these challenges often leads to trade-offs concerning the other two (see e.g. [1] for a more detailed discussion). Policy makers frequently look to power and energy system optimisation models to balance these dimensions and, to the extent that such models can operationalise the trilemma, map out internally consistent low carbon futures for these systems.

Variable renewables, i.e. those whose output varies because it is dependent on the weather and we define here as onshore and offshore wind and solar photovoltaics (PV), have a central role in low carbon power systems owing to their rapid cost reductions in recent decades. Indeed, onshore wind and solar PV are quickly approaching cost parity with the cheapest forms of fossil fuel power [2] and cost reductions are expected to continue. Therefore, high shares of VREs are an increasingly common theme emerging from long-term power system planning studies that employ cost-optimising models (see e.g. [3]-[5]).

However, the limited capability of such models to encapsulate the holistic definition of the energy trilemma is 
one of their central limitations. Typically, sustainability is operationalised as greenhouse gas or $\mathrm{CO}_{2}$ emissions, without considering the wider, often abstract and qualitative, dimensions of sustainability. The inclusion of such factors in energy research has been advocated for some time (see e.g. [6], [7]). One such aspect is the impact that VRE plants have on the landscape and the way in which this is perceived, tolerated (or not) and the potential impacts upon the general population. The spatial coincidence of landscapes both perceived as beautiful and with particularly high VRE resources creates a tension between two partly opposing objectives, which is especially significant for onshore wind. This visual impact is one of the major drivers that can act to undermine the public acceptability of wind energy in such communities [8]-[10] and in turn limit its deployment. In addition, the sheer spatial scale associated with significant VRE deployment can lead to competition with agricultural land uses, as is the case with solar PV.

Studies that assess the potential for VREs have attempted to consider various criteria that can restrict the deployment of onshore wind. For example, the visual impact of onshore wind on the resulting feasible potential has been analysed in Austria [11], Denmark [12] and Baden-Württemberg [13]. The latter study employed data on survey-based valuations of the landscape aesthetics amongst the general population, in order to exclude especially scenic areas, a similar approach to the one employed in the present paper. Reference [13] concluded that, in a moderate scenario in terms of public acceptance, the technical potential for onshore wind generation in BadenWürttemberg (from [14]) was roughly halved. In a similar approach, but also engaging stakeholders in an iterative participatory framework, [11] found that Austria's technical onshore wind generation potential is reduced by in excess of 95\% when considering the multitude of factors that can restrict its deployment. Yet this study stopped short of linking their socially acceptable capacity potentials with a power system planning model.

Efforts have been made to combine this type of analysis with techno-economic energy systems modelling (see e.g. [3], [15], [16]) to constrain the optimisation in an attempt to reflect more realistic and publicly acceptable contributions from VREs. But none of these studies has considered social barriers to siting by engaging actual stakeholders and/or drawing on empirical data. In order to close this research gap, this paper combines empirical data on landscape aesthetics (or scenicness) and VRE capacity potentials with a power system model that makes planning and operational decisions. We focus on a case study for Great Britain's (GB) power system in 2050, which is constrained to be part of a wider energy system that meets the country's net-zero greenhouse gas emissions target. We use a spatially-explicit assessment of onshore and offshore wind capacity potentials based on technical restrictions and crowd-sourced scenicness data from the website Scenic-Or-Not ${ }^{l}$. We augment these with a detailed analysis of GB's solar PV capacity potential. Using this modelling framework, we assess the implications on the electricity system, in terms of costs and design, of different

\footnotetext{
${ }^{1} \mathrm{http}: / /$ scenicornot.datasciencelab.co.uk/
}

levels of public sensitivity to the visual landscape impact associated with VRE deployment.

This paper is structured as follows: in section II we describe the model and methodology used here, section III provides a discussion of the results and section IV summarises the insights emerging from this study.

\section{Methodology}

Fig. 1. Provides an overview of the methodology described in subsections A through D below.

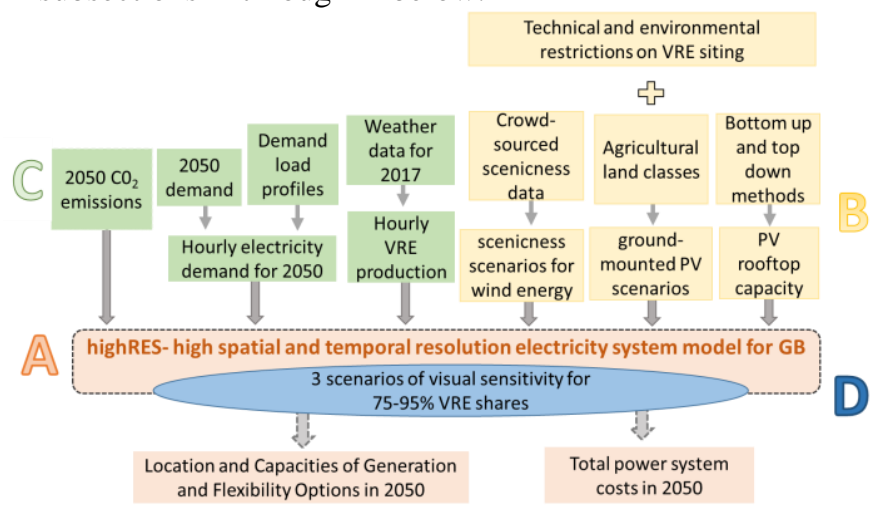

Fig. 1 Flowchart of the methodology used here.

\section{A. The highRES model}

highRES is a cost-minimising model of the GB electricity system written in the General Algebraic Modelling System (GAMS) language. It simultaneously optimises spatiallyexplicit capacity investment, based on annualised costs, as well as hourly dispatch of the power system so that supply matches demand in every hour of the year, in each of 20 zones that spatially represent $\mathrm{GB}$, at least cost. In terms of low carbon generation it considers three VREs (solar PV - ground and roof mounted are considered one technology, onshore and offshore wind), nuclear, and natural gas combined cycle turbines with CCS (NGCGT-CCS). All generation capacity that exists today is assumed to be retired by 2050 apart from Hinkley Point C. To integrate renewables into the system we model natural gas open cycle turbines (NGOCGT), electricity storage in the form of grid-scale Lithium Ion batteries (with an 8 hour discharge duration) and reinforcement of the transmission system within GB. The transmission network is represented using a computationally efficient linear transshipment formulation, i.e. a transport model in which power flows between zones in a controlled manner (see [17] for more discussion). The $2.8 \mathrm{GW}$ of pumped hydro currently on the GB system is also operationally available to the model but no further capacity investment was permitted. The model incorporates $8.4 \mathrm{GW}$ of interconnection to Europe/Ireland (based on existing and planned links currently under construction) and this capacity is fixed in all model runs. The European electricity price for 2050 is taken from the EU's Reference Scenario, which assumes a $48 \%$ reduction in GHG emissions relative to 1990 by 2050 , developed by [18]. The cost assumptions we use here for generation and storage are given in Table I. All costs are given in 2010 GBP and taken from the UK TIMES model [19] unless otherwise stated. 
TABLE I

Technology cost assumptions

\begin{tabular}{|c|c|c|c|c|c|}
\hline $\begin{array}{l}\text { Technolog } \\
\text { y }\end{array}$ & $\begin{array}{l}\text { Capex } \\
(£ / k W)\end{array}$ & $\begin{array}{l}\text { Variable } \\
\text { O \& M } \\
\text { (£/kWh) }\end{array}$ & $\begin{array}{l}\text { Fixed } \\
0 \& \mathrm{M} \\
(£ / \mathrm{kW})\end{array}$ & $\begin{array}{l}\text { Fuel } \\
\text { costs } \\
(£ / k W h)\end{array}$ & $\begin{array}{l}\text { Start-up } \\
\text { cost } \\
\text { (£/start) }\end{array}$ \\
\hline $\begin{array}{l}\text { Onshore } \\
\text { wind }\end{array}$ & 730 [20] & 0.002 & 23 & NA & NA \\
\hline $\begin{array}{l}\text { Offshore } \\
\text { wind }\end{array}$ & 1340 [21] & 0.003 & 86 & NA & NA \\
\hline Solar & $400[22]$ & 0.001 & 6.9 & NA & NA \\
\hline $\begin{array}{l}\text { NGCCGT- } \\
\text { CCS }\end{array}$ & 1179 & 0.001 & 33 & 0.024 & $\begin{array}{l}141,000 \\
{[23]}\end{array}$ \\
\hline Nuclear & 3973 & 0.004 & 80.2 & 0.006 & $\begin{array}{l}195,000 \\
{[23]}\end{array}$ \\
\hline NGOCGT & 286 & 0.001 & 13.7 & 0.024 & $\begin{array}{l}3,100 \\
{[23]}\end{array}$ \\
\hline $\begin{array}{l}\text { Li-ion } \\
\text { batteries } \\
\text { (Power) }\end{array}$ & $52[24]$ & 0 & 6.7 & NA & NA \\
\hline $\begin{array}{l}\text { Li-ion } \\
\text { batteries } \\
\text { (Energy) }\end{array}$ & $\begin{array}{l}62[24] \\
(\mathfrak{f} / \mathrm{kWh})\end{array}$ & NA & 0 & NA & NA \\
\hline
\end{tabular}

highRES is a "snapshot" model in that it designs a system for a given year, in this case 2050, that meets all constraints placed upon it. The formulation of the model has previously been described in detail in [16], [25] and here we only describe additional equations that have been added for this study. These additions have been made to increase the fidelity of the model by better representing: a) the technical details of thermal plant operation and b) security of supply, which is particularly relevant in highly renewable systems. The capacity deployment and operation of thermal plant are presented as clustered units following [26], [27]:

$$
\begin{aligned}
& U_{t, z, g} \leq N_{z, g} \\
& U_{t, z, g}=U_{t-1, z, g}+U P_{t, z, g}-D O W N_{t, z, g} \\
& U_{t, z, g} \cdot p_{g}^{\max } \cdot a f_{g} \geq P_{t, z, g}+O R_{t, z, g}+F R_{t, z, g} \\
& P_{t, z, g} \geq U_{t, z, g} \cdot p_{g}^{\min } \\
& U_{t, z, g} \geq \sum_{t-\min _{g}^{u p}}^{t} U P_{t, z, g} \\
& N_{g}-U_{t, z, g} \geq \sum_{t-\min _{g}^{\text {down }}}^{t} D O W N_{t, z, g} \\
& \left(N_{g}-U_{t, z, g}\right) \cdot p_{g}^{\max } \cdot a f_{g} \geq O R_{t, z, g}^{q u i c k} g=N G O C G T \\
& O R_{t, z, g} \leq U_{t, z, g} \cdot o r_{g}^{\max } \\
& F R_{t, z, g} \leq U_{t, z, g} \cdot \text { frg }_{g}^{\max }
\end{aligned}
$$

Here: (1) limits the number of committed units to the number actually deployed, (2) is a commitment balance between hours, (3) limits maximum generation, (4) limits minimum generation, (5)-(6) ensure minimum up and down times, respectively, are enforced, (7) limits the provision of operating reserve while offline to NGOCGT only due to its rapid start up capability and (8)-(9) limits the provision of operating reserve and frequency response by a generator cluster to the maximum ramp achievable in the relevant time window (20 minutes for operating reserve, 10 seconds for frequency response). In this formulation the integer decision variables are relaxed to be continuous for NGOCGT, due to its small individual unit capacity, while continuing to expose this technology to all the operational constraints detailed above. Technical assumptions for the clustered units are given in Table II and taken from UK TIMES unless otherwise stated.

TABLE II

\section{Technical assumptions}

\begin{tabular}{|llllll|}
$\begin{array}{l}\text { Technolog } \\
\mathrm{y}\end{array}$ & $\begin{array}{l}\text { Inerti } \\
\mathrm{a}(\mathrm{s})\end{array}$ & $\begin{array}{l}\text { Unit } \\
\text { size } \\
(\mathrm{MW}\end{array}$ & $\begin{array}{l}\text { Min } \\
\text { stable } \\
\text { generatio } \\
\mathrm{n}(\%)\end{array}$ & $\begin{array}{l}\text { Min } \\
\text { up/down } \\
\text { time } \\
\text { (hours) }\end{array}$ & $\begin{array}{l}\mathrm{CO2} \\
\mathrm{emissions} \\
(\mathrm{gCO} 2 / \mathrm{kWh}\end{array}$ \\
$\begin{array}{l}\text { NGCCGT- } \\
\text { CCS }\end{array}$ & $5[28]$ & 750 & $50[28]$ & $4 / 4[23]$ & 44 \\
\hline Nuclear & $7[28]$ & 1650 & 50 & $24 / 8[23]$ & 0 \\
\hline NGOCGT & $5[28]$ & 50 & $20[28]$ & $1 / 1[29]$ & 528 \\
\hline
\end{tabular}

The model has been further augmented to represent security of supply provision (i.e. reserve/response) by energy storage technologies as follows:

$$
\begin{aligned}
& S C A P_{z, s} \cdot a f_{s} \geq P_{t, z, s}+O R_{t, z, s}+F R_{t, z, s} \\
& O R_{t, z, s} \leq S C A P_{z, s} \cdot a f_{s} \cdot s_{-} o r_{s}^{\max } \\
& F R_{t, z, s} \leq S C A P_{z, s} \cdot a f_{s} \cdot s_{-} f r_{s}^{\max } \\
& S L E V E L_{t, z, s} \geq O R_{t, z, s}+F R_{t, z, s}
\end{aligned}
$$

Here (10) restricts the provision of power and reserve/response, (11)-(12) limits the provision of reserve/response based on the fraction of total storage capacity that can come online within the reserve/response time window and (13) ensures the provided reserve/response are limited to the energy stored in the storage system at that time step. Storage technologies are represented in a continuous fashion, i.e. not as integer units. Operating reserve is then aggregated by:

$$
\begin{aligned}
& O R_{t}^{r e q} \geq O R_{t, z, g}+O R_{t, z, s}+O R_{t, z, g}^{q u i c k} \\
& O R_{t}^{r e q}=D E M_{t} \cdot D E M^{\text {uncert }}+ \\
& \sum_{z} \sum_{g=\text { wind,solar }} P_{t, z, g} \cdot V R E_{g}^{\text {uncert }}
\end{aligned}
$$

The hourly operating reserve requirement in (15) is driven by an assumed uncertainty in demand (5\%) and VRE output forecasts $(12 \%$ for solar and $14 \%$ wind, taken from the UK's Transmission System Operator $^{2}$ ) and is based on a formulation proposed by [30]. These constraints require the model to schedule sufficient operating or quick start reserve so the

\footnotetext{
${ }^{2}$ https://www.nationalgrideso.com/sites/eso/files/documents/Quarterly\%20 Forecasting\%20Report-\%20June\%2017.pdf
} 
system can contend with these uncertainties. Finally, frequency response is aggregated as follows:

$F R_{t}^{r e q} \geq F R_{t, z, g}+F R_{t, z, s}$

The hourly frequency response requirement in (16) is set using a linearised approximation derived by [28]. The response requirement is the amount of power which must be injected into the system within 10 seconds to arrest the decline in system frequency following a sudden loss of generation and prevent it falling below the stipulated minimum of $49.2 \mathrm{~Hz}$. Reference [28] derive a function (equation 38 in that work) that relates this requirement to system inertia such that lower levels of inertia require greater amounts of responsive power to be scheduled within the aforementioned time window. Here hourly system inertia is estimated according to equation (32) from [28].

\section{B. VRE land use scenarios}

During optimisation highRES must respect the exogenously defined VRE capacity potentials per zone and technology. As touched upon earlier, here these are derived in a spatially detailed manner based on crowd-sourced data from the website Scenic-or-Not. This resource allows users to upload, geotag and rate the perceived scenicness of pictures from landscapes all across GB on a scale of 1 to 10 , with 1 being least scenic. The Scenic-or-Not dataset is based on images sourced from Geograph ${ }^{3}$ covering nearly $95 \%$ of the $1 \mathrm{~km}$ grid squares of Great Britain and contains a total of 1,536,054 ratings. Based on this raw data, [31] employed machine learning in order to interpolate and fill in the missing areas based on land use categories.

The average scenicness value for a given location then provides an indication of how picturesque that site is typically regarded to be. In the present case only $1 \mathrm{~km}^{2}$ grid squares with three or more votes were employed in order to avoid outliers. The methodology for employing this scenicness data to derive resource potentials for VREs in GB is based on [32]. Here we provide a short summary, for further details the reader is referred to the full report.

The first step in this analysis involved a logistic regression between scenicness and planning applications for onshore wind and ground-mounted $\mathrm{PV}$ in $\mathrm{GB}^{4}$. The regression demonstrated that, while not related to the likelihood of success of ground-mounted PV applications, there is a significant negative correlation for onshore wind (odds ratio $0.71-0.86$ for a $95 \%$ confidence interval at $99 \%$ significance), i.e. a higher scenicness value leads to a greater likelihood of rejection of a planning application. From this, it can be concluded that scenicness is strongly related to the deployment of onshore wind, but not for ground-mounted PV. Due to a relative paucity of planning applications, we also make the assumption that scenicness does not impact the likelihood of success of roof-mounted PV projects. Furthermore, we assume that, in a similar way to [13], scenicness can be employed as a proxy for the level of visual

\footnotetext{
${ }^{3} \mathrm{http}: / /$ www.geograph.org.uk/

${ }^{4} \mathrm{https} / / / \mathrm{www} . g o v . u k / g o v e r n m e n t / p u b l i c a t i o n s / r e n e w a b l e-e n e r g y-$ planning-database-monthly-extract
}

impact that onshore wind would have within a particular landscape.

The next step in the analysis is to determine the capacity deployment potentials for all three VREs based on a suitable set of constraints. For onshore wind, we develop a technical potential (i.e. before applying the scenicness data) using essentially the same method as that presented in [33], [34], whereby, for example, residential areas, land near airports and roads, as well as national parks and gradients over $20^{\circ}$ are excluded and buffer distances inserted. Further details can be found in [32]. We then use these potential data to develop three scenicness scenarios, which progressively decrease the land area available in each zone on which the model is permitted to deploy onshore wind. Based on a statistical analysis of the distribution of the scenincess data, we opt for scenicness thresholds of 7,5 and 3 , each of which roughly includes an equal share of the dataset. This means that all sites with values greater than this are restricted, which exclude $8 \%$, $40 \%$ and $87 \%$ of locations respectively.

For offshore wind we take the "medium" restrictiveness scenario from [16] as our technical potential and additionally apply visual impact spatial buffers around the coast based on the scenicness data. This involves restricting offshore wind deployment out to a distance of $44 \mathrm{~km} \mathrm{[35]} \mathrm{for} \mathrm{sections} \mathrm{of} \mathrm{the}$ coast that exceed our scenicness thresholds.

The available spatial area for solar PV deployment is distinguished between rooftop and ground-mounted systems. The former is determined through a combination of bottom-up [36], based on satellite images and open maps to automatically recognise rooftop geometry, and top-down [37] approaches. The bottom-up method was applied to four GB cities (London, Leeds, Birmingham and Glasgow) and the results employed to derive floor:roof area ratios and inclination/azimuth angles for the whole country. For ground-mounted PV, baseline spatial restrictions include, for example, removing land that is steeper than $15^{\circ}$ or is protected. Guidance from the Department for Communities and Local Government ${ }^{5}$ stipulates that preference should be given to poor agricultural land quality for the development of ground-mounted PV. Therefore, we use the agricultural land grade system, that classifies land based on its suitability for crop production with grade 1 being best and grade 5 worst, to exclude areas of grade 1 and 2 . We further develop a more restrictive case to capture land use competition between $\mathrm{PV}$ and food/biomass production by excluding grade 3 land as well. For further details, see [32]. To convert available land area per zone to a capacity potential for each VRE technology we use land use footprints of 40, 3 and $5 \mathrm{MW} / \mathrm{km}^{2}$ for solar $\mathrm{PV}$, onshore and offshore wind respectively. The rationale for these values is explained in more detail in [16].

\section{2050 Power system boundaries}

To ensure the power systems designed by highRES are in line with the UK's recently updated Climate Change Act, i.e. net-zero greenhouse gas emissions by 2050 from the whole UK economy, we constrain annual $\mathrm{CO}_{2}$ emissions to be at most $3 \mathrm{MtCO}_{2}$ based on the Further Ambition scenario from [38]. Hourly demands input into highRES are based on

\footnotetext{
${ }^{5}$ https://www.gov.uk/guidance/renewable-and-low-carbon-energy
} 
rescaled metered hourly electricity demand for 2017 from National Grid (GB's transmission system operator). This process uses the 2050 annual demand from the Committee on Climate Changes's (CCC) net-zero report, excluding demand from electrified heat in buildings and electric vehicles, which amounts to $373 \mathrm{TWh}$. Electrified heat is then added on assuming 133 TWh of annual electricity demand. This is adjusted from the $146 \mathrm{TWh}$ specified in the CCC's report because 2017 was a relatively warm year, assessed based on the number of heating degree days per year over the period 1993-2017. The percentage difference between the median number of heating degree days over this period and those for 2017 is used to make the adjustment. The annual demand for heating is distributed to the daily level according to the heating degree days in 2017 and then to the hourly level using an average heat pump profile derived from [39]. Annual electric vehicle demand of $76.4 \mathrm{TWh}$ is shared out according to the hourly resolution diurnal charging profile from [40], i.e. the annual demand is multiplied by a time series created from 365 copies of the daily profile. This process provides an estimate of hourly electricity demand in 2050, which we assume to be inelastic. Total annual demand is then $574 \mathrm{TWh}$. Finally, to align with the demand year, 2017 weather data from the climate reanalysis ERA5 ${ }^{6}$ (wind speeds, $2 \mathrm{~m}$ air temperature) and CMSAF SARAH2 ${ }^{7}$ (solar irradiance) is used to drive VRE production in each zone.

\section{Scenario analysis}

We use the capacity potentials described previously to assess the cost and system design impacts of different levels of scenicness, which we take to be a suitable proxy for local sensitivity to visual impact of wind deployment. For example, excluding land with a scenicness value greater than 3 represents a high sensitivity to visual impact. Conversely, only preventing VRE deployment in highly scenic areas (i.e. > 7) would indicate a low sensitivity to visual impact and a higher public acceptance at the local level. Therefore, hereafter, we refer to our scenicness scenarios as Low, Moderate (excluding scenicness > 5) and High sensitivity restrictions.

Initial testing indicated that varying the solar PV and offshore wind scenarios had very little impact on total system cost. For the former, this is because solar PV capacity potential is dominated by ground-mounted installations which even under more restrictive land-use assumptions still provide a large potential due to the relatively high power density (MW/km2). For the latter, GB has an extensive offshore wind capacity potential because of the shallow and large North Sea. Therefore, we limit our investigation to onshore wind, varying its potential based on the three scenicness thresholds described previously, with offshore wind and solar PV fixed at their highest restriction.

TABLE III

VRE capacity potential scenarios used here

\begin{tabular}{|c|c|c|c|c|}
\hline Technology & $\begin{array}{l}\text { Restriction } \\
\text { level and } \\
\text { Scenicness } \\
\text { excluded }\end{array}$ & $\begin{array}{l}\text { Total } \\
\text { national } \\
\text { area } \\
\text { available }\end{array}$ & $\begin{array}{l}\text { Fraction of } \\
\text { GB land } \\
\text { (onshore) } \\
\text { or UK }\end{array}$ & $\begin{array}{l}\text { Capacity } \\
\text { potential } \\
(\mathrm{GW})\end{array}$ \\
\hline
\end{tabular}

\footnotetext{
${ }^{6} \mathrm{https}: / / \mathrm{www} . e \mathrm{emwf}$.int/en/forecasts/datasets/reanalysis-datasets/era5
}

${ }^{7}$ www.cmsaf.eu

\begin{tabular}{|c|c|c|c|c|}
\hline & & km2) & $\begin{array}{l}\text { Renewable } \\
\text { Energy } \\
\text { Zone } \\
\text { (offshore) } \\
\text { area (\%) }\end{array}$ & \\
\hline Solar & $\begin{array}{l}\text { Low, no } \\
\text { scenicness limit }\end{array}$ & 91,614 & 40 & 3,665 \\
\hline Solar & $\begin{array}{l}\text { High, no } \\
\text { scenicness limit }\end{array}$ & 13,818 & 6 & 553 \\
\hline $\begin{array}{l}\text { Offshore } \\
\text { wind }\end{array}$ & $\begin{array}{l}\text { Low, Scenicness } \\
>7\end{array}$ & 94,466 & 13 & 472 \\
\hline $\begin{array}{l}\text { Offshore } \\
\text { wind }\end{array}$ & $\begin{array}{l}\text { Moderate, } \\
\text { Scenicness }>5\end{array}$ & 91,593 & 13 & 458 \\
\hline $\begin{array}{l}\text { Offshore } \\
\text { wind }\end{array}$ & $\begin{array}{l}\text { High, } \\
\text { Scenicness }>3\end{array}$ & 91,434 & 13 & 457 \\
\hline $\begin{array}{l}\text { Onshore } \\
\text { wind }\end{array}$ & $\begin{array}{l}\text { Low, Scenicness } \\
>7\end{array}$ & 60,343 & 26 & 181 \\
\hline $\begin{array}{l}\text { Onshore } \\
\text { wind }\end{array}$ & $\begin{array}{l}\text { Moderate, } \\
\text { Scenicness }>5\end{array}$ & 34,451 & 15 & 103 \\
\hline $\begin{array}{l}\text { Onshore } \\
\text { wind }\end{array}$ & $\begin{array}{l}\text { High, } \\
\text { Scenicness }>3\end{array}$ & 6,575 & 3 & 19.7 \\
\hline
\end{tabular}

In addition, we consider this in the context of five VRE shares meaning that the model designs a system which is cost optimal while requiring $75-95 \%$ of annual generation to come from VREs, in 5\% steps. We stop at $95 \%$ because the current formulation of our model requires a minimum system inertia of 41.25 GWs assuming a maximum rate of change of frequency of $1 \mathrm{~Hz} / \mathrm{s}$ and a largest loss of $1650 \mathrm{MW}$ - one unit of Hinkley Point C. This in turn implies a minimum amount of synchronous generation must be online in each hour, resulting in a minimum of $\sim 5 \%$ annual generation.

\section{RESULTS AND DISCUSSION}

\section{A. Capacity potential maps and supply curves}

Before discussing the results emerging from highRES, it is prudent to elaborate how our sensitivity scenarios shape the potential for onshore wind. With this in mind, in the first row of Fig. 2 we present maps of the three sensitivity thresholds considered here. Each map demonstrates how a progressively higher sensitivity leads to the exclusion of more and more land from onshore wind development. In addition, they also show how certain areas of GB are perceived to have more beautiful landscapes than others, e.g. Western Scotland.

In the middle row of panels of Fig. 2, we show maps of capacity potential based on aggregating the detailed land availability data in the first row to the 20 zones represented in the optimisation model and then converting this area to a capacity limit using a footprint of $3 \mathrm{MW} / \mathrm{km}^{2}$. Here we clearly see the reduction in capacity potential per zone as more land is excluded when moving from our Low to High sensitivity scenario. Indeed, some prominent zones such as those in Scotland and the South-West have their potentials cut from $\sim 20$ and $\sim 15 \mathrm{GW}$ respectively to less than $5 \mathrm{GW}$.

The bottom row of panels in Fig. 2 then demonstrates the impact that sensitivity to visual impact has on the supply curve of onshore wind energy input into the model. At Low, onshore wind can provide in excess of $400 \mathrm{TWh} / \mathrm{yr}$. However, in the most stringent case this is reduced to $50 \mathrm{TWh} / \mathrm{yr}$. We stress once more that the model makes investment and dispatch decisions at an hourly resolution based on time series of zonal VRE capacity factors, and that their annual aggregation as 
supply curves neglects important factors such as timing of production and costs associated with transmission line reinforcement. Nevertheless, these panels do provide useful clarity on the implications of our sensitivity scenarios for onshore wind in GB.

\section{B. Capacity mix}

We now move on to explore the results output from our optimisation modelling. In the left panel of Fig. 3 we show the national installed capacity of generation and storage at each VRE share for our Low scenario. In the middle and right hand panels of this figure we also show how changing the scenario alters the wider power system in terms of these capacities.

Considering the left panel first, the total installed capacity of the system initially grows steadily with increasing VRE share, as one might expect, until a large jump when moving from 90 to $95 \%$ penetration. In all cases the capacity mix is, predictably, dominated by variable renewables with onshore wind initially being the largest component, while the capacity of solar PV and, to a lesser extent, offshore wind and battery storage, grows at higher VRE shares.

Both the central and right panels of Fig. 3 demonstrate how the model is forced to switch from onshore wind to greater deployment of offshore wind and solar PV when moving to the High scenario. The extent to which this shift occurs grows both as a function of increasing VRE share and sensitivity to visual impact. Furthermore, at the highest shares and most limited land availability, the system requires substantially more batteries and to a lesser extent NGCCGT-CCS for balancing and to meet security constraints. We note that while nuclear capacity reduces with increasing VRE share it, generally, does not change across our sensitivity scenarios.
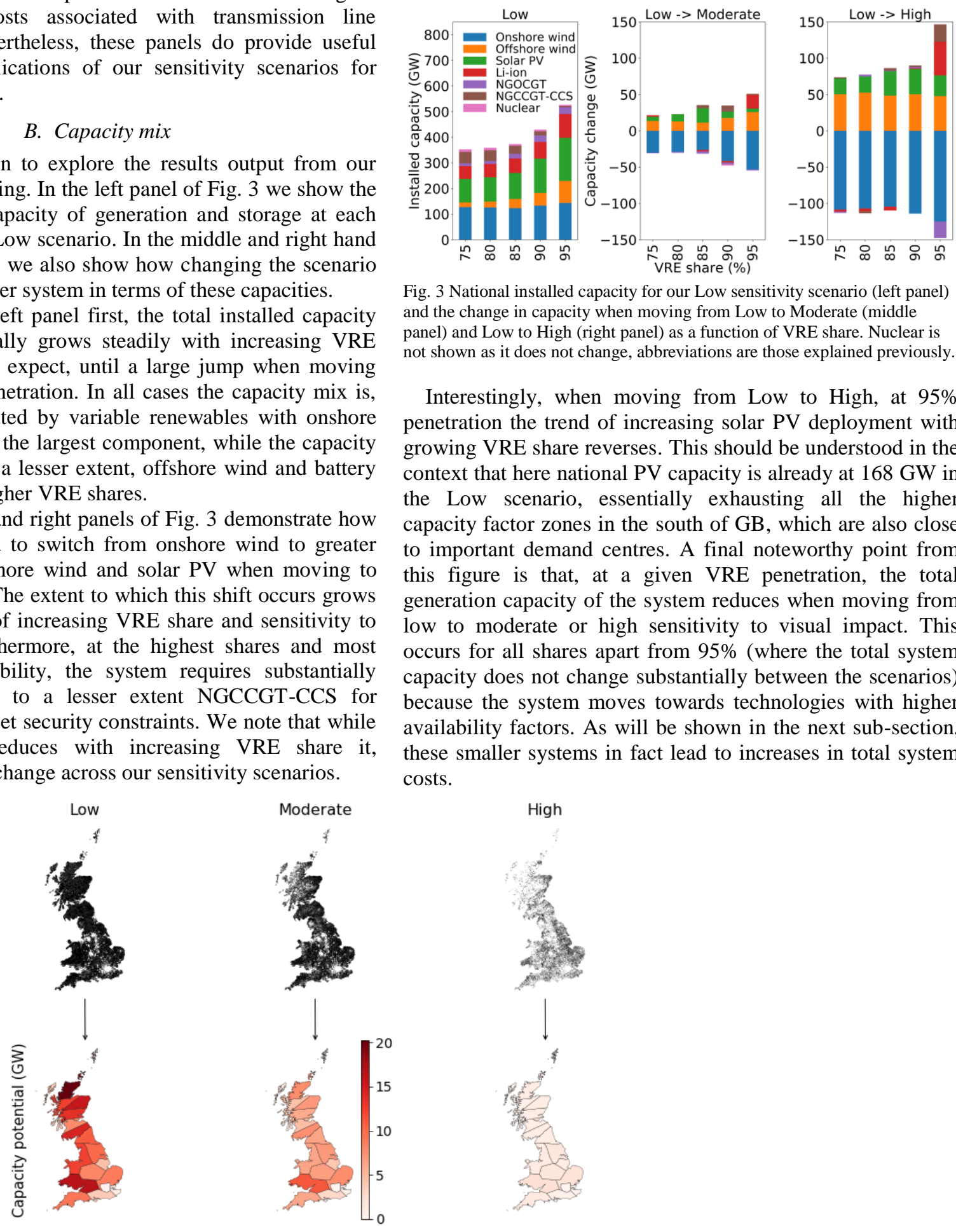

Fig. 3 National installed capacity for our Low sensitivity scenario (left panel) and the change in capacity when moving from Low to Moderate (middle panel) and Low to High (right panel) as a function of VRE share. Nuclear is not shown as it does not change, abbreviations are those explained previously.

Interestingly, when moving from Low to High, at 95\% penetration the trend of increasing solar PV deployment with growing VRE share reverses. This should be understood in the context that here national PV capacity is already at $168 \mathrm{GW}$ in the Low scenario, essentially exhausting all the higher capacity factor zones in the south of GB, which are also close to important demand centres. A final noteworthy point from this figure is that, at a given VRE penetration, the total generation capacity of the system reduces when moving from low to moderate or high sensitivity to visual impact. This occurs for all shares apart from $95 \%$ (where the total system capacity does not change substantially between the scenarios) because the system moves towards technologies with higher availability factors. As will be shown in the next sub-section, these smaller systems in fact lead to increases in total system costs.
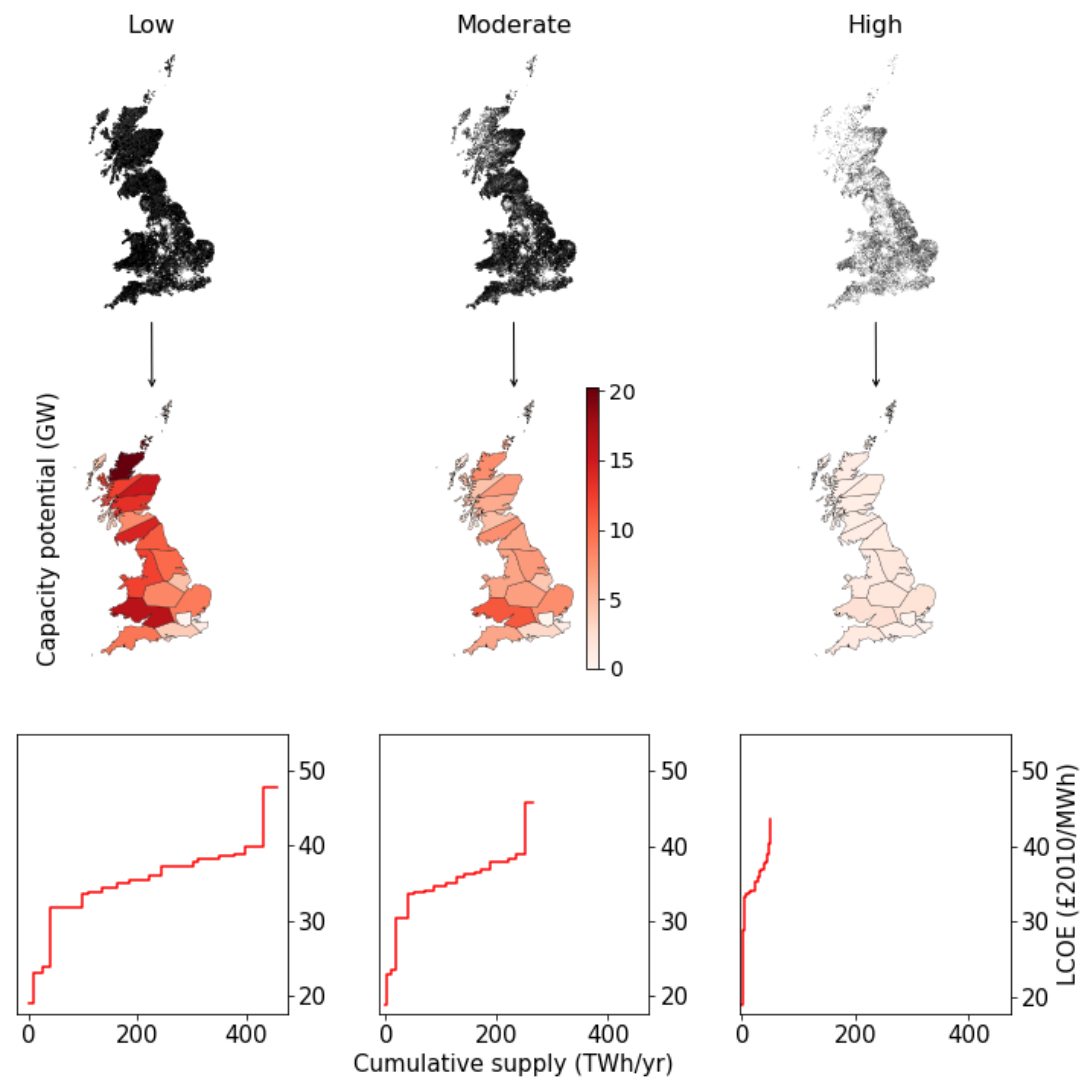

Fig. 2 The impact of the three different visual impact sensitivity scenarios spanned here on capacity potentials and supply curves. In the first row, black areas are land where onshore wind can be deployed. The second row shows the resultant capacity potential (in GW) per zone for the 20 balancing zones in highRES. The available land is aggregated into these zones and then converted to a capacity potential. The third row shows the supply curve for onshore wind with 20 steps, 0885-89 each one corresponding to a zone. 
To demonstrate the repercussions of the different sensitivity scenarios used here on the spatial deployment pattern of onshore wind, in Fig. 4 we plot the zonal capacity for our Low scenario (left panel) and the change in capacity when moving to Moderate or High (middle and right panels respectively). Due to space restrictions we only show this for an $85 \%$ VRE share. The left panel highlights that capacity is spread throughout the country, with particular concentrations in Northern Scotland and the South-West. This is because the system benefits in cost terms from such spatial diversity as it is able to leverage the fact that different locations experience different weather conditions at the same time.

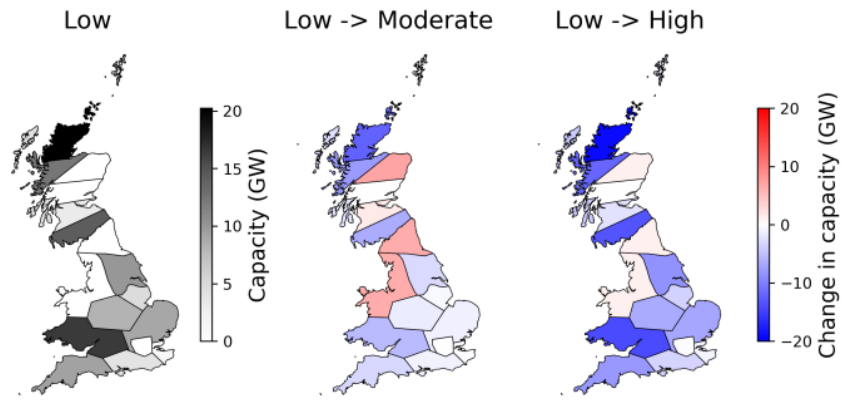

Fig. 4 Spatially explicit onshore wind capacity deployment for our Low scenario (left panel) and the change in capacity when moving to our Moderate (mid panel) and High (right panel) scenarios. These plots show the case for an $85 \%$ VRE share in annual generation.

The Moderate sensitivity constraint results in large reductions in Scotland, emphasising how picturesque that part of GB is perceived to be. At the same time certain zones see an increase of capacity as deployment in other, more costeffective zones, is constrained. Moving to the right panel, onshore capacity is now heavily restricted across the country (see also Fig. 3), with Scotland and the South-West of GB losing in excess of $30 \mathrm{GW}$ and $20 \mathrm{GW}$ each, respectively. Only very small increases in onshore wind capacity are now observed due to the restrictive nature of this threshold over the entirety of GB. Furthermore, because some parts of GB are considered to be more scenic than others, e.g. Scotland, here we see that the amount of spatial diversity available also becomes progressively restricted.

\section{Total system cost}

In this section we focus on the impact on total system cost of our scenarios of public sensitivity to the visual impact of onshore wind deployment. In Fig. 5 we plot the total system levelised cost of electricity (LCOE) computed by dividing total system costs by total generation as a function of VRE share. We also show the change in system LCOE that occurs when moving from our Low scenario to Moderate or High, again for all five VRE shares we consider.

From the left panel we immediately see that $85 \%$ penetration is the lowest cost system but that $75-85 \%$ shares all have relatively comparable costs. This highlights that, as other studies such as those discussed in the introduction have shown, systems which are predominately powered by variable renewables are increasingly seen as the future of very low carbon electricity. It is only at $90 \%$ and above that system LCOE begins to rise rapidly. As touched upon previously, this is due to the substantial increase in extra installed VRE capacity and batteries necessary to integrate them into the system.
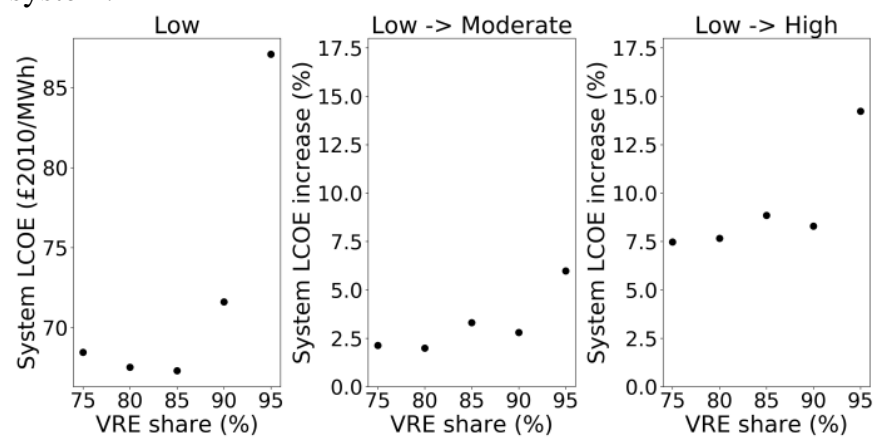

Fig. 5 Total system levelised cost of electricity for our least restrictive sensitivity threshold (left panel) and the change in total system LCOE when moving to the Moderate (middle panel) and High (right panel) scenarios as a function of VRE share in annual generation.

The middle and right panels of Fig. 5 highlight that moving to a more restrictive sensitivity scenario results in an increase in system LCOE. In the former, initially this uptick is $~ 2 \%$ but this grows with VRE share up to $\sim 6 \%$ at the highest share considered here. When moving to the most stringent visual impact scenario (right panel) we see a minimum increase of $\sim 7.5 \%$ which rises steadily to over $8 \%$ at $90 \%$ penetration before growing markedly to $14.2 \%$ if we push to $95 \%$ variable renewables. Again, this can be understood by looking at the capacity changes plotted in Fig 3, particularly the increased requirement for offshore wind, batteries and CCGT-CCS to replace onshore wind while also managing system stability.

These results demonstrate that the cost implications of factoring in the public's potential sensitivity to the visual impact of onshore wind can be large and grow at higher shares of VRE. This is particularly relevant as policy makers push toward systems that produce $100 \%$ of their electricity needs from VREs and highlights the potential repercussions if local communities do not support such an objective. We therefore emphasise that if onshore wind is to feature heavily in power systems of the future, it is critical that decision-makers find the necessary tools to ameliorate its visual impact and ensure an inclusive and just transition for local communities. Here we show that, in doing so, policy makers will also be able to keep low carbon electricity as cost-effective as possible.

\section{Methodological limitations}

We note that there are some limitations to this study. From a power system optimisation perspective, we constrain interconnection capacity with Europe to that which either exists today or is under construction. More interconnection would provide more flexibility to the system and could reduce the system cost impacts we find. However, the importance of domestic energy security and uncertainties associated with Brexit raises questions about the extent of this reduction. In a similar vein, we do not model demand side measures, which would be another source of flexibility, due to significant uncertainty around the scale of their utilisation. We also only consider a single combination of annual electricity demand and emissions. Furthermore, while technically possible, VREs do not provide any response/reserve services in this paper. Finally, we note that only onshore wind has social constraints 
factored into its siting whereas other potentially contentious technologies, for example CCS, do not. This means our results may be under estimating the system LCOE increase associated with moving to more restrictive onshore wind scenarios.

The scenicness-based capacity potentials also have limitations. Firstly, depending on the cut-off criteria, the locations are either scenic or not in a binary manner. In reality, landscapes can be partially scenic. Secondly, we describe locations by their average scenicness, but we don't include the number of voters (i.e. a site with an average scenicness of 5 is treated the same whether it is based on 4 or 40 votes). Thirdly, we do not account for how many people are affected by the "loss of scenicness". Fourthly, here we focus on only one component of the public acceptance of onshore wind. Other factors which could influence acceptance include, for example, perceived procedural fairness, perceived fair distribution of costs and benefits and shadow flicker. Thus we stress that simply ameliorating visual impact alone may not make onshore wind acceptable.

All these caveats would be of interest to explore in future research.

\section{CONCLUSIONS}

In this paper we have used a case study for Great Britain to understand the implications of factoring in one aspect of the public acceptance of onshore wind on highly renewable power systems. To do this we employed empirical data that quantifies the scenicness of landscapes across GB and then developed three scenarios of spatially explicit capacity potentials to represent differing sensitivity levels of local communities to the visual impact of onshore wind. We fed these capacity potentials into a cost-optimising power system model to understand the impact on system costs and designs. A summary of the key insights from this study are as follows:

- An increasing sensitivity to the visual impact of onshore wind results in a substantial capacity potential reduction, which drives a drop of as much as $89 \%$ in the total supply potential of onshore wind per year.

- As the role of onshore wind is progressively constrained, the system is reoriented toward deploying more offshore wind and solar PV. Given this less optimal configuration of VREs in terms of their technological and spatial diversity, there is also an increased requirement for batteries and, to a lesser extent, dispatchable generation. In general, the higher the VRE share, the greater the increase in capacity of these technologies when moving to a more restrictive sensitivity threshold, although there are some exceptions.

- We find that some of the most picturesque parts of GB also happen to be the most cost-effective for onshore wind, leading to large reductions in installed capacity as we move through our sensitivity scenarios. In particular, deployment is heavily limited in Scotland and the South-West which in turn acts to limit the spatial diversity of onshore wind.

- Our results indicate that the extent to which local communities are sensitive to onshore wind's visual impact can have a direct bearing on the levelised cost of electricity of the system. Initially this is low at a $2 \%$ increase of system LCOE but can grow to up to $14.2 \%$ for a high sensitivity and share of VREs in annual generation. We argue it is essential for policy makers to consider these cost implications and to find mechanisms to ameliorate the visual impact of onshore wind in local communities.

This study represents a first step in bringing together empirically grounded assessments of VRE siting restrictions with a long term power system planning model in an attempt to improve the fidelity of the latter. In a future study it would be of great interest to design and implement a participatory framework where a broad range of stakeholders can iteratively engage with the optimisation modelling, thereby helping its insights to gain further real world traction.

\section{ACKNOWLEDGEMENTS}

The authors gratefully acknowledge the support of David Schlund, who carried out some of the analysis of onshore wind potentials whilst a Student Assistant at KIT, Germany, as well as Camille Moutard, whose Master Thesis at DTU (as cited in the text) provided some helpful inputs to this work. The usual disclaimer applies.

\section{REFERENCES}

[1] R. J. Heffron and D. McCauley, 'The concept of energy justice across the disciplines', Energy Policy, vol. 105, pp. 658-667, Jun. 2017, doi: 10.1016/j.enpol.2017.03.018.

[2] IRENA, 'Renewable power generation costs in 2018 ', 2018.

[3] A. E. MacDonald, C. T. M. Clack, A. Alexander, A. Dunbar, J. Wilczak, and Y. Xie, 'Future cost-competitive electricity systems and their impact on US CO2 emissions', Nat. Clim. Change, vol. 6, no. 5, pp. 526-531, Jan. 2016, doi: 10.1038/nclimate2921.

[4] H. C. Gils, Y. Scholz, T. Pregger, D. Luca de Tena, and D. Heide, 'Integrated modelling of variable renewable energy-based power supply in Europe', Energy, vol. 123, pp. 173-188, Mar. 2017, doi: 10.1016/j.energy.2017.01.115.

[5] D. P. Schlachtberger, T. Brown, M. Schäfer, S. Schramm, and M. Greiner, 'Cost optimal scenarios of a future highly renewable European electricity system: Exploring the influence of weather data, cost parameters and policy constraints', Energy, vol. 163, pp. 100 114, Nov. 2018, doi: 10.1016/j.energy.2018.08.070.

[6] B. K. Sovacool, 'Diversity: Energy studies need social science', Nature, vol. 511, no. 7511, pp. 529-530, Jul. 2014, doi: $10.1038 / 511529 a$.

[7] L. Steg, 'Limiting climate change requires research on climate action', Nat. Clim. Change, vol. 8, no. 9, pp. 759-761, Sep. 2018, doi: 10.1038/s41558-018-0269-8.

[8] P. Devine- Wright, 'Beyond NIMBYism: towards an integrated framework for understanding public perceptions of wind energy', Wind Energy, vol. 8, no. 2, pp. 125-139, 2005, doi: 10.1002/we.124.

[9] R. Wüstenhagen, M. Wolsink, and M. J. Bürer, 'Social acceptance of renewable energy innovation: An introduction to the concept', Energy Policy, vol. 35, no. 5, pp. 2683-2691, May 2007, doi: 10.1016/j.enpol.2006.12.001.

[10] C. R. Jones and J. Richard Eiser, "Understanding "local" opposition to wind development in the UK: How big is a backyard?', Energy Policy, vol. 38, no. 6, pp. 3106-3117, Jun. 2010, doi: 10.1016/j.enpol.2010.01.051.

[11] S. Höltinger, B. Salak, T. Schauppenlehner, P. Scherhaufer, and J. Schmidt, 'Austria's wind energy potential - A participatory modeling approach to assess socio-political and market acceptance', Energy Policy, vol. 98, pp. 49-61, Nov. 2016, doi: 10.1016/j.enpol.2016.08.010.

[12] J. Ladenburg, 'Does more wind energy influence the choice of location for wind power development? Assessing the cumulative effects of daily wind turbine encounters in Denmark', Energy Res. Soc. Sci., vol. 10, pp. 26-30, Nov. 2015, doi:

10.1016/j.erss.2015.06.005.

[13] T. Jäger, R. McKenna, and W. Fichtner, 'The feasible onshore wind energy potential in Baden-Württemberg: A bottom-up methodology considering socio-economic constraints', Renew. Energy, vol. 96, pp. 662-675, Oct. 2016, doi: 10.1016/j.renene.2016.05.013. 
[14] R. McKenna, S. Gantenbein, and W. Fichtner, 'Determination of costpotential-curves for wind energy in the German federal state of Baden-Württemberg', Energy Policy, vol. 57, pp. 194-203, Jun. 2013, doi: 10.1016/j.enpol.2013.01.043.

[15] S. Samsatli, I. Staffell, and N. J. Samsatli, 'Optimal design and operation of integrated wind-hydrogen-electricity networks for decarbonising the domestic transport sector in Great Britain', Int. J. Hydrog. Energy, vol. 41, no. 1, pp. 447-475, Jan. 2016, doi: 10.1016/j.ijhydene.2015.10.032.

[16] J. Price, M. Zeyringer, D. Konadu, Z. Sobral Mourão, A. Moore, and E. Sharp, 'Low carbon electricity systems for Great Britain in 2050: An energy-land-water perspective', Appl. Energy, vol. 228, pp. 928941, Oct. 2018, doi: 10.1016/j.apenergy.2018.06.127.

[17] W. Matar and A. M. Elshurafa, 'Electricity transmission formulations in multi-sector national planning models: An illustration using the KAPSARC energy model', Energy Rep., vol. 4, pp. 328-340, Nov. 2018, doi: 10.1016/j.egyr.2018.04.004.

[18] P. Capros, EU Reference Scenario 2016, Energy, transport and GHG emissions Trends to 2050. Luxembourg: Publications Office of the European Union. 2016.

[19] H. E. Daly, K. Scott, N. Strachan, and J. Barrett, 'Indirect $\mathrm{CO}_{2}$ Emission Implications of Energy System Pathways: Linking IO and TIMES Models for the UK', Environ. Sci. Technol., vol. 49, no. 17, pp. 10701-10709, Sep. 2015, doi: 10.1021/acs.est.5b01020.

[20] JRC, 'Cost development of low carbon energy technologies', 2018.

[21] BVGassociates, 'Future renewable energy costs: Offshore wind', 2017.

[22] R. Lacal Arantegui et al., 'ETRI 2014 - Energy Technology Reference Indicator projections for 2010-2050', Publications Office of the European Union, EUR - Scientific and Technical Research Reports, 2014.

[23] J. P. Deane, Á. Driscoll, and B. P. Ó. Gallachóir, 'Quantifying the impacts of national renewable electricity ambitions using a NorthWest European electricity market model', Renew. Energy, vol. 80, pp. 604-609, Aug. 2015, doi: 10.1016/j.renene.2015.02.048.

[24] O. Schmidt, S. Melchior, A. Hawkes, and I. Staffell, 'Projecting the Future Levelized Cost of Electricity Storage Technologies', Joule, vol. 3, no. 1, pp. 81-100, Jan. 2019, doi: 10.1016/j.joule.2018.12.008.

[25] M. Zeyringer, J. Price, B. Fais, P.-H. Li, and E. Sharp, 'Designing low-carbon power systems for Great Britain in 2050 that are robust to the spatiotemporal and inter-annual variability of weather', Nat. Energy, vol. 3, no. 5, pp. 395-403, May 2018, doi: 10.1038/s41560018-0128-x.

[26] B. Palmintier and M. Webster, 'Impact of unit commitment constraints on generation expansion planning with renewables', in 2011 IEEE Power and Energy Society General Meeting, 2011, pp. 17, doi: 10.1109/PES.2011.6038963.

[27] B. Palmintier, 'Flexibility in generation planning: Identifying key operating constraints', in 2014 Power Systems Computation Conference, 2014, pp. 1-7, doi: 10.1109/PSCC.2014.7038323.

[28] F. Teng and G. Strbac, 'Full Stochastic Scheduling for Low-Carbon Electricity Systems', IEEE Trans. Autom. Sci. Eng., vol. 14, no. 2, pp. 461-470, Apr. 2017, doi: 10.1109/TASE.2016.2629479.

[29] C. F. Heuberger, I. Staffell, N. Shah, and N. Mac Dowell, 'Impact of myopic decision-making and disruptive events in power systems planning', Nat. Energy, vol. 3, no. 8, pp. 634-640, Aug. 2018, doi: 10.1038/s41560-018-0159-3.

[30] C. F. Heuberger, I. Staffell, N. Shah, and N. M. Dowell, 'A systems approach to quantifying the value of power generation and energy storage technologies in future electricity networks', Comput. Chem. Eng., vol. 107, pp. 247-256, Dec. 2017, doi: 10.1016/j.compchemeng.2017.05.012.

[31] C. I. Seresinhe, T. Preis, and H. S. Moat, 'Using deep learning to quantify the beauty of outdoor places', R. Soc. Open Sci., vol. 4, no. 7, p. 170170, doi: 10.1098/rsos.170170.

[32] C. Moutard, 'Assessing the potentials and costs of onshore wind and solar PV in Great Britain, under consideration of scenicness and land use competition', Master Thesis, DTU, 2019.

[33] R. McKenna, S. Hollnaicher, and W. Fichtner, 'Cost-potential curves for onshore wind energy: A high-resolution analysis for Germany', Appl. Energy, vol. 115, pp. 103-115, Feb. 2014, doi: 10.1016/j.apenergy.2013.10.030.

[34] R. McKenna, S. Hollnaicher, P. Ostman v. d. Leye, and W. Fichtner, 'Cost-potentials for large onshore wind turbines in Europe', Energy, vol. 83, pp. 217-229, Apr. 2015, doi: 10.1016/j.energy.2015.02.016.
[35] R. G. Sullivan, L. B. Kirchler, J. Cothren, and S. L. Winters, 'Research Articles: Offshore Wind Turbine Visibility and Visual Impact Threshold Distances', Environ. Pract., vol. 15, no. 1, pp. 33 49, Mar. 2013, doi: 10.1017/S1466046612000464.

[36] K. Mainzer, S. Killinger, R. McKenna, and W. Fichtner, 'Assessment of rooftop photovoltaic potentials at the urban level using publicly available geodata and image recognition techniques', Sol. Energy, vol. 155, pp. 561-573, Oct. 2017, doi: 10.1016/j.solener.2017.06.065.

[37] K. Mainzer, K. Fath, R. McKenna, J. Stengel, W. Fichtner, and F. Schultmann, 'A high-resolution determination of the technical potential for residential-roof-mounted photovoltaic systems in Germany', Sol. Energy, vol. 105, pp. 715-731, Jul. 2014, doi: 10.1016/j.solener.2014.04.015.

[38] Committee on Climate Change, 'Net Zero - Technical Report', 2019.

[39] J. Love et al., 'The addition of heat pump electricity load profiles to GB electricity demand: Evidence from a heat pump field trial', Appl. Energy, vol. 204, pp. 332-342, Oct. 2017, doi: 10.1016/j.apenergy.2017.07.026.

[40] T. Boßmann and I. Staffell, 'The shape of future electricity demand: Exploring load curves in 2050s Germany and Britain', Energy, vol. 90, pp. 1317-1333, Oct. 2015, doi: 10.1016/j.energy.2015.06.082. 